\title{
Amide-Linked C4"-Saccharide Modification of KRN7000 Provides Potent Stimulation of Human Invariant NKT Cells and Anti-Tumor Immunity in a Humanized Mouse Model
}

Noemi Alejandra Saavedra-Avila ${ }^{\ddagger}$, Santosh Keshipeddy ${ }^{\dagger}$, Matthew J. Guberman-Pfeffer ${ }^{\dagger}$, Ayax

Pérez-Gallegos"', Neeraj K. Saini", Carolina Schäfer"', Leandro J. Carreño"', José A Gascón', Steven A. Porcelli, ${ }^{*, \S}$ and Amy R. Howell ${ }^{*},+$

${ }^{\dagger}$ Department of Chemistry, The University of Connecticut, Storrs, Connecticut 06269-3060, United States tDepartment of Microbiology and Immunology, ${ }^{\S}$ Department of Medicine, and "Department of Pediatrics (Genetic Medicine) Albert Einstein College of Medicine, Bronx, New York 10461, United States

" ' 'Millennium Institute on Immunology and Immunotherapy, Programa de Inmunología, Instituto de Ciencias Biomédicas, Facultad de Medicina, Universidad de Chile, Santiago 8380453, Chile.

Contents:

Supplemental Fig. S1 - Gating for flow cytometry analysis

Supplemental Fig. S2 - Simulation interaction diagram (SID) for the mouse CD1d-TCR complex

Supplemental Fig. S3 - Representative snapshots along the MD simulation for the mouse CD1d-TCR complex

Descriptions of movie (.mpg) files

Experimental procedures and characterization of synthetic products, including ${ }^{1} \mathrm{H}$ NMR of key intermediates and compounds 8-10 


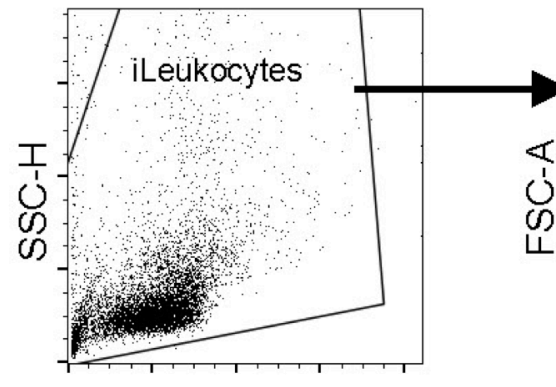

FSC-H

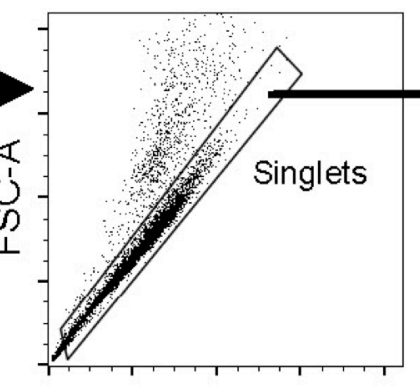

FSC-H
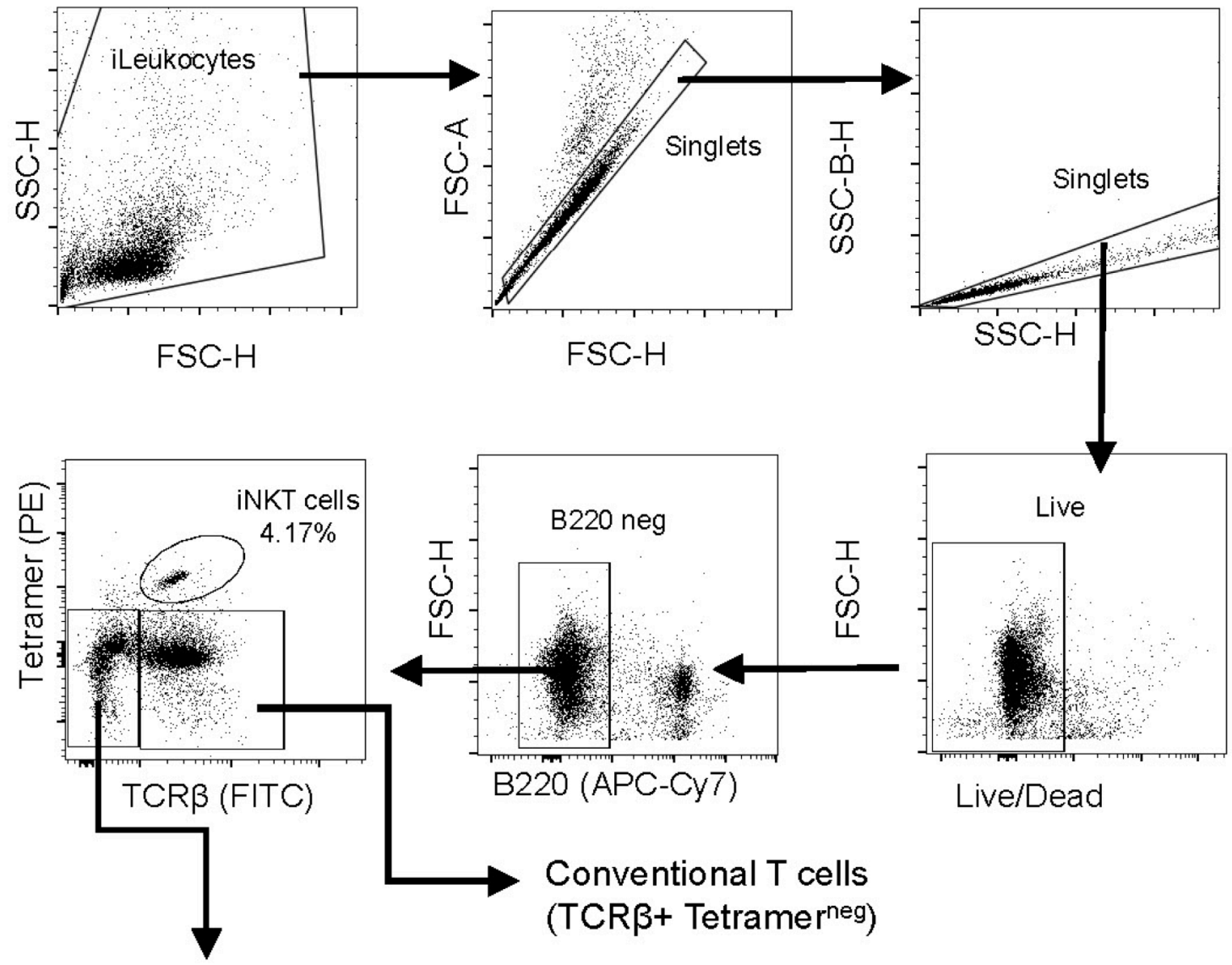

Live/Dead

\section{Conventional T cells}

$\left(\mathrm{TCR} \beta+\right.$ Tetramer $\left.{ }^{\text {neg }}\right)$

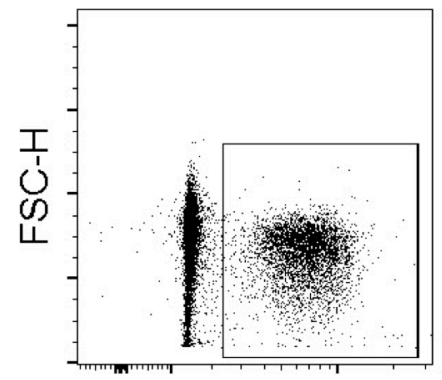

\section{NK cells}

(NK1.1+ TCR $\beta^{\text {neg }}$ Tetramer $\left.{ }^{\text {neg }}\right)$

NK1.1 (BV786)

Supplemental Figure S1. Gating strategy for flow cytometry analysis of iNKT cells, NK cells and conventional T cells. Gating strategy is shown for identification and quantitation of iNKT cells in liver mononuclear cell suspensions. Conventional T cells are also identified in the TCR $\beta$ and tetramer negative region of the terminal plot in the sequence. NK cells were identified by gating on NK1.1 positive cells within the TCR $\beta$ negative region of the tetramer versus TCR $\beta$ plot, and all cell types were analyzed for expression of intracellular markers (not shown) including T-bet, GATA-3, IFNY and granzyme B (see Figs. 4 and 5). 


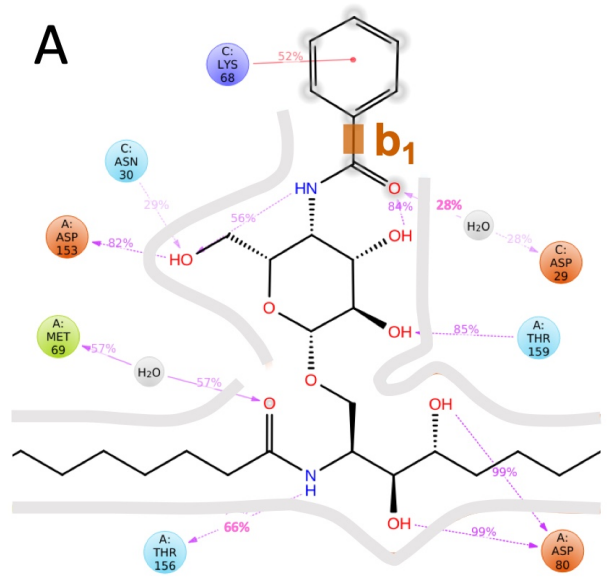

B
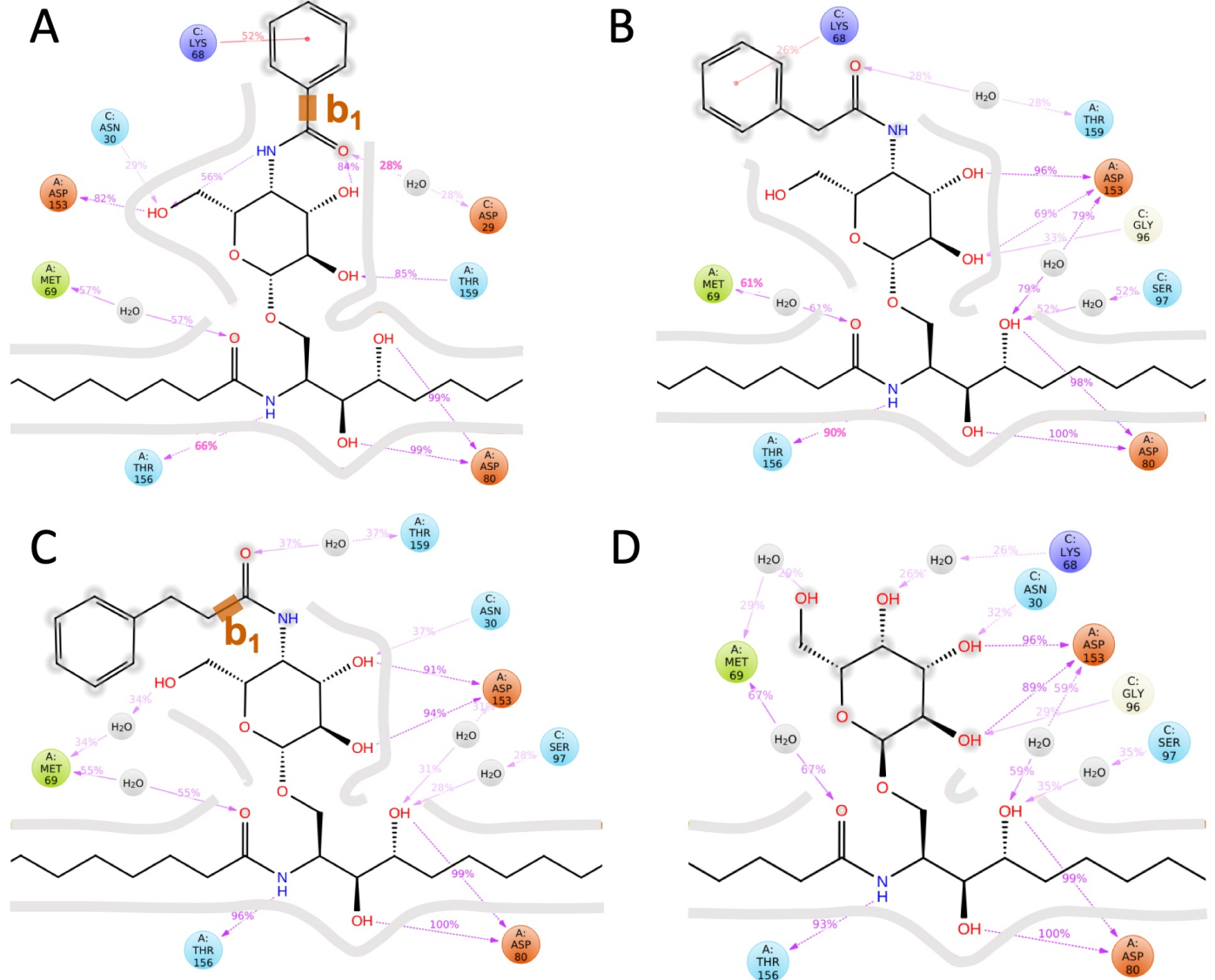

D

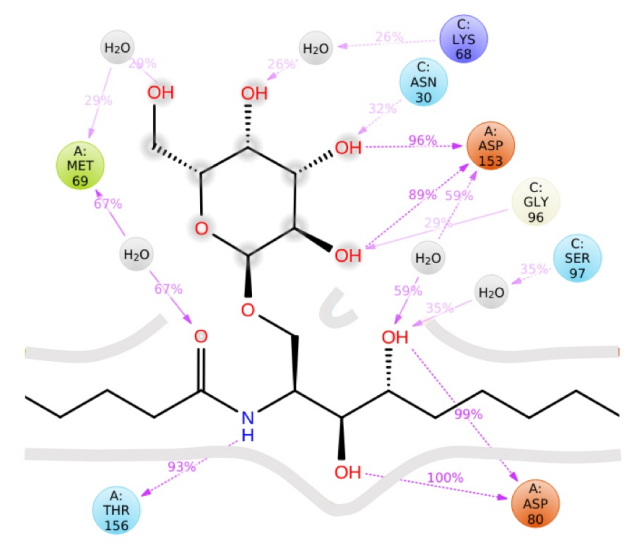

Charged (negative) Charged (positive)

Hydrophobic Polar

(1) Water $\longrightarrow$ Pi-cation

Supplemental Figure S2. Simulation interaction diagram (SID) for the mouse CD1D-TCR complex with $8(A), 9(B), 10(C)$, and KRN7000 (D). Percentages indicate the fraction of time a given residues interacts with the ligand. Only interactions with an occurrence larger than $25 \%$ are displayed. The bond adjacent to the amide group (b1) is highlighted in orange for analysis of dihedral angles. Contour lines give an approximation to the protein cavity based on the strength of the ligand-protein interactions. 


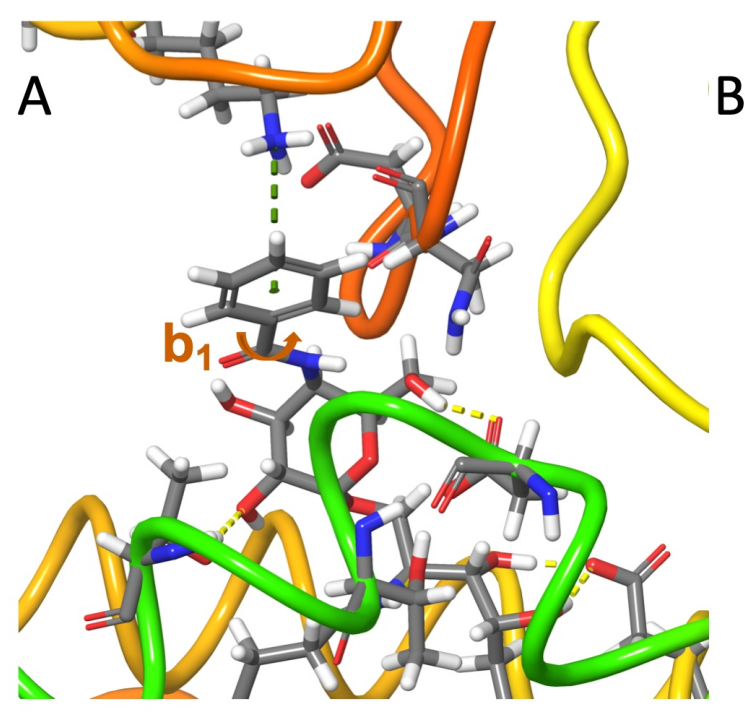

Mouse 8
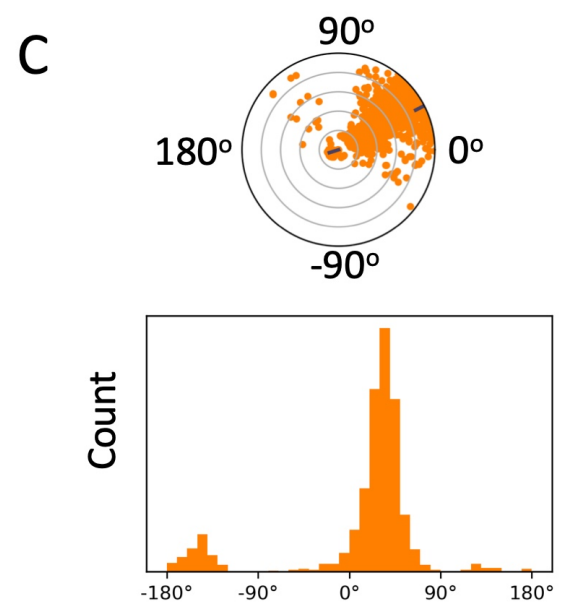

B

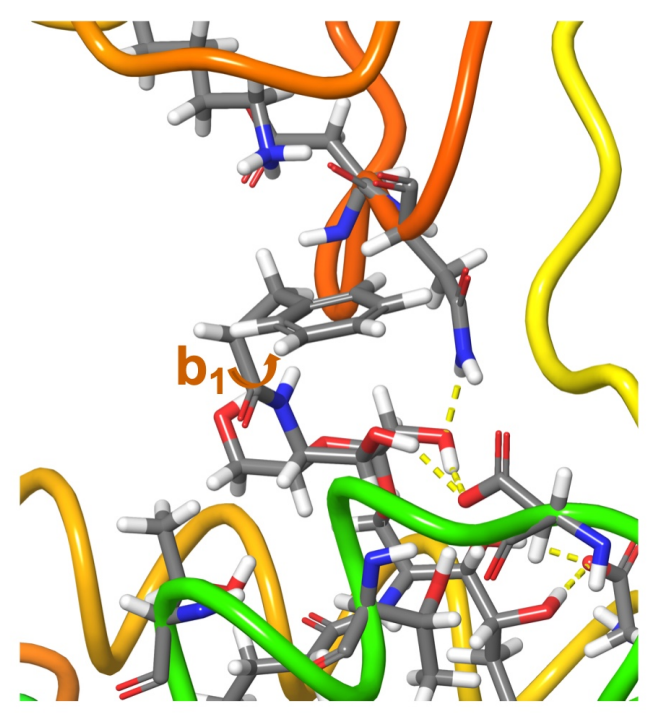

Mouse 10

D
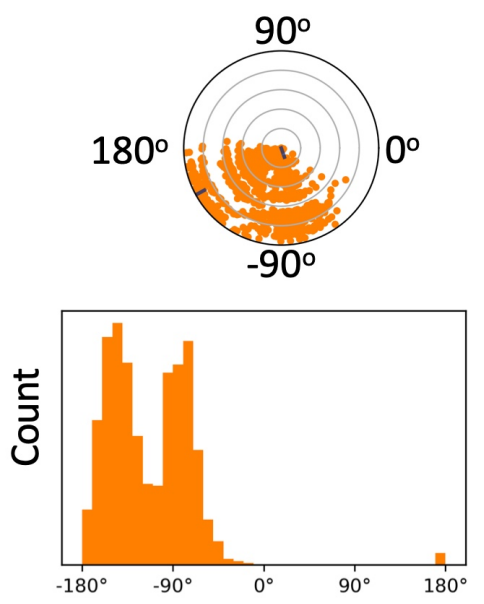

Supplemental Figure S3. Representative snapshots along the MD simulation for the mouse CD1d-TCR complex with 8 (A) and 10 (B). Yellow dashed lines indicate hydrogen bonds and green dashed lines indicate $\pi$-cation interactions. Panels $C$ and $D$ show the distribution of the dihedral angle of the bond adjacent to the amide group throughout the MD simulation for 8 and 10, respectively. The marked bimodal distribution in 10 indicates larger displacements of the ethyl-phenyl group. Water molecules are not displayed. Also worth noting is the non-standard conformation of the sugar in $\mathbf{8}$. 
Description of movie files: 310K-H-AH10-1.mpeg, 310K-H-AH10-2.mpeg, and 310K-H-AH103.mpeg contain mpeg files that show the movement of ligands $\mathbf{8}, \mathbf{9}$, and $\mathbf{1 0}$, respectively, inside the cavity at $310 \mathrm{~K}$ for a period of 50 nanoseconds for human CD1d-TCR. In all these movies, hydrogen bonds are colored with yellow dashed lines and $\pi-\pi$ stacking interactions with light blue dashed lines 310K-H-AH10-1.mpeg: Ligand 8 is shown with carbon atoms colored blue. The phenyl group interacts mainly with $\mathrm{CD} 1 \mathrm{~d}-\mathrm{His} 68$ via $\pi-\pi$ stacking remaining restrained inside the cavity.

310K-H-AH10-2.mpeg: Ligand 9 is shown with carbon atoms colored green. The phenyl group alternates between interacting with CD1d-Trp153 and TCR-Phe51 via $\pi-\pi$ stacking, while remaining mostly restrained between these two residues.

310K-H-AH10-3.mpeg: Ligand 10 is shown with carbon atoms colored brown. The phenyl group displays a very low percentage of specific $\pi-\pi$ stacking interactions and undergoes larger displacements within the cavity.

\section{Experimental procedures for glycolipid synthesis}

General Experimental. KRN7000 is commercially available (Avanti Polar Lipids). AH10-7 was prepared as previously reported. ${ }^{1}$ All chemicals, solvents and deuterated solvents were purchased from Sigma-Aldrich, Alfa-Aesar, Oakwood Chemicals, TCl or Fisher Scientific and used as received unless noted. Methylene chloride (DCM) was dried over $\mathrm{CaH}_{2}$. Deuterated chloroform $\left(\mathrm{CDCl}_{3}\right)$ was dried over activated $4 \AA$ molecular sieves. All reactions, unless specified, were conducted under an atmosphere of $\mathrm{N}_{2}$ in glassware that had been oven or flame dried. ${ }^{1} \mathrm{H}$ NMR spectra were recorded at $400 \mathrm{MHz}$ and/or at $500 \mathrm{MHz}$ and calibrated to the residual $\mathrm{CHCl}_{3}$ peak at $7.26 \mathrm{ppm}$, the pyridine signal at $8.74 \mathrm{ppm}$ or TMS at $0.00 \mathrm{ppm} .{ }^{13} \mathrm{C}$ NMR spectra were recorded at $100 \mathrm{MHz}$ and/or at $125 \mathrm{MHz}$ and calibrated to the $\mathrm{CDCl}_{3}$ peak at 77.2 ppm, the pyridine peak at $150.4 \mathrm{ppm}$ or TMS at $0.0 \mathrm{ppm}$. Chemical shifts are reported in units of parts per million (ppm). Infrared (IR) spectra were recorded on an FT-IR spectrophotometer and are reported in $\mathrm{cm}^{-1}$. High-resolution mass spectra were obtained on an AccuTOF instrument at the University of Connecticut. Specific rotations $[\alpha]_{D}$ were obtained on a JASCO P-2000 polarimeter, using the sodium D-line as a source, and the concentration (c) is expressed in $\mathrm{g}$ 
per $100 \mathrm{~mL}$. Flash or gravity column chromatography was performed on silica gel, 40 microns, 32-63 flash silica. Thin layer chromatography was performed on silica gel (silica gel $60 \mathrm{~F}_{254}$ ) glass plates, and the compounds were visualized by UV and/or $5 \%$ phosphomolybdic acid in ethanol. Proton and carbon NMR spectra of purified intermediates and final products are below.

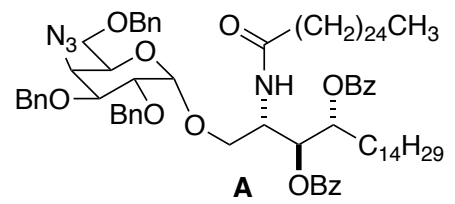

(2S,3S,4R)-3,4-Di-O-benzoyl-1-O-(2",3",6"-tri-O-benzyl-4"-azido-a-D-galactopyranosyl)-2-

(N-hexacosanoylamino)octadecan-1,3,4-triol (A). Phenyl 2,3,6-tri-O-benzyl-4-azido-1-thio- $\beta$ D-galactopyranoside $(11)^{2}(70 \mathrm{mg}, 0.12 \mathrm{mmol})$ was azeotroped with $(2 S, 3 S, 4 R)-3,4-\mathrm{di}-\mathrm{O}$ benzoyl-2-( $N$-hexacosanoylamino)octadecan-1,3,4-triol $(12)^{3-4}(0.16 \mathrm{~g}, 0.17 \mathrm{mmol})$ in toluene (3 $x 10 \mathrm{~mL})$. The mixture was dissolved in DCM $(3.0 \mathrm{~mL})$ under $\mathrm{N}_{2}$, and freshly ground $4 \AA \mathrm{MS}$ (50 $\mathrm{mg}$ ) were added. The mixture was cooled to $-40{ }^{\circ} \mathrm{C}$ (dry-ice $/ \mathrm{CH}_{3} \mathrm{CN}$ ), and $\mathrm{N}$-iodosuccinimide (36 $\mathrm{mg}, 0.16 \mathrm{mmol})$ and silver triflate $(10 \mathrm{mg}, 0.041 \mathrm{mmol})$ were added. The mixture was stirred at $0{ }^{\circ} \mathrm{C}$ until the donor was consumed (based on TLC). Stirring was continued an additional 10-20 $\mathrm{min}$ at $0^{\circ} \mathrm{C}$, followed by the addition of $\mathrm{Et}_{3} \mathrm{~N}(2 \mathrm{~mL})$. The reaction mixture was diluted with DCM $(10 \mathrm{~mL})$ and filtered through Celite. The filtrate was concentrated. Purification by flash chromatography on silica gel (petroleum ether/EtOAc 90:10) afforded A as a colorless oil (80 $\mathrm{mg}, 48 \%$ ): $[\alpha]^{25}{ }_{\mathrm{D}}+18.1\left(\mathrm{c} 1.0, \mathrm{CH}_{2} \mathrm{Cl}_{2}\right.$ ); IR (neat) 2921, 2852, 2104, 1720, $1679 \mathrm{~cm}^{-1} ;{ }^{1} \mathrm{H} \mathrm{NMR}$ $\left(400 \mathrm{MHz}, \mathrm{CDCl}_{3}\right) \delta 7.97(\mathrm{~d}, J=7.7 \mathrm{~Hz}, 2 \mathrm{H}), 7.88(\mathrm{~d}, J=7.7 \mathrm{~Hz}, 2 \mathrm{H}), 7.53(\mathrm{dd}, J=7.4,7.4 \mathrm{~Hz}$, 1H), $7.46(\mathrm{dd}, J=7.4,7.4 \mathrm{~Hz}, 1 \mathrm{H}), 7.39(\mathrm{dd}, J=7.7,7.7 \mathrm{~Hz}, 2 \mathrm{H}), 7.32-7.20(\mathrm{~m}, 12 \mathrm{H})$, 7.14-7.11 (m, 5H), $6.63(\mathrm{~d}, J=9.5 \mathrm{~Hz}, 1 \mathrm{H}), 5.61(\mathrm{dd}, J=9.3,2.4 \mathrm{~Hz}, 1 \mathrm{H}), 5.33(\mathrm{~m}, 1 \mathrm{H})$, 4.66-4.60 (m, 3H), 4.59-4.49 (m, 4H), $4.43(\mathrm{~d}, J=12.0 \mathrm{~Hz}, 1 \mathrm{H}), 4.05(\mathrm{dd}, J=6.3,6.3 \mathrm{~Hz}, 1 \mathrm{H})$, 3.88-3.82 (m, 3H), $3.72(\mathrm{dd}, J=9.3,3.5 \mathrm{~Hz}, 1 \mathrm{H}), 3.56(\mathrm{dd}, J=11.4,2.0 \mathrm{~Hz}, 1 \mathrm{H}), 3.48(\mathrm{~m}, 1 \mathrm{H})$, $3.43(\mathrm{~m}, 1 \mathrm{H}), 2.09(\mathrm{t}, J=7.5 \mathrm{~Hz}, 2 \mathrm{H}), 1.82(\mathrm{~m}, 2 \mathrm{H}), 1.56(\mathrm{~m}, 2 \mathrm{H}), 1.20(\mathrm{br} \mathrm{s}, 68 \mathrm{H}), 0.83-0.80$ 
$(\mathrm{m}, 6 \mathrm{H}) ;{ }^{13} \mathrm{C}$ NMR $\left(100 \mathrm{MHz}, \mathrm{CDCl}_{3}\right) \delta 173.3,166.3,165.5,138.3,138.2,137.7,133.5,133.1$ $130.3,130.0,130.0,130.0,128.7,128.6,128.6,128.5,128.2,128.1,128.0,127.9,127.9,100.0$ 77.6, 76.6, 73.9, 73.8, 73.7, 73.3, 72.6, 70.2, 69.2, 68.3, 61.5, 48.8, 36.9, 32.1, 29.9, 29.9, 29.8, 29.8, 29.7, 29.6, 29.6, 28.6, 25.9, 22.9, 14.3; HRMS (ESI) calculated for $\mathrm{C}_{85} \mathrm{H}_{124} \mathrm{~N}_{4} \mathrm{NaO}_{10}(\mathrm{M}+$ $\mathrm{Na})^{+} \mathrm{m} / \mathrm{z}:$ 1383.9210. Found: 1383.9217.

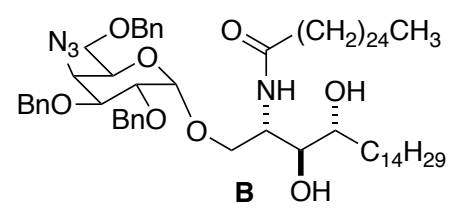

(2S,3S,4R)-1-O-(2",3",6"-Tri-O-benzyl-4"-azido-a-D-galactopyranosyl)-2-(N-

hexacosanoylamino)octadecane-1,3,4-triol (B). NaOMe in $\mathrm{MeOH}(0.43 \mathrm{~mL}, 0.22 \mathrm{mmol})$ was added to a stirred solution of $(2 S, 3 S, 4 R)-3,4-d i-O-b e n z o y l-1-O-(2 ", 3 ", 6$ "-tri-O-benzyl-4"-azido-aD-galactopyranosyl)-2-( $N$-hexacosanoylamino)octadecan-1,3,4-triol (A) $(0.14 \mathrm{~g}, 0.10 \mathrm{mmol})$ in THF (4 mL) and $\mathrm{MeOH}(12 \mathrm{~mL})$. The mixture was stirred at RT until the starting material was consumed (based on TLC). The reaction mixture was neutralized with Dowex $\mathrm{H}^{+}$and filtered through Celite, and the filter cake was washed with THF $(2 \times 10 \mathrm{~mL})$. The filtrate was concentrated, and the residue was purified by flash chromatography on silica gel (petroleum ether/EtOAc 70:30), affording $B$ as a white solid $(100 \mathrm{mg}, 84 \%): \mathrm{mp} 68-70{ }^{\circ} \mathrm{C} ;[\alpha]^{25}{ }_{\mathrm{D}}+31.7(\mathrm{c}$ 2.5, $\mathrm{CH}_{2} \mathrm{Cl}_{2}$ ); IR (neat) 2917, 2849, 2109, 1641, 1096, $1036 \mathrm{~cm}^{-1} ;{ }^{1} \mathrm{H} \mathrm{NMR}\left(500 \mathrm{MHz}, \mathrm{CDCl}_{3}\right) \delta$ 7.38-7.28 (m, 15H), $6.32(\mathrm{~d}, J=8.3 \mathrm{~Hz}, 1 \mathrm{H}), 4.85(\mathrm{~d}, J=11.5 \mathrm{~Hz}, 1 \mathrm{H}), 4.78-4.71(\mathrm{~m}, 3 \mathrm{H}), 4.63$ $(\mathrm{d}, J=11.5 \mathrm{~Hz}, 1 \mathrm{H}), 4.54(\mathrm{~d}, J=11.6 \mathrm{~Hz}, 1 \mathrm{H}), 4.48(\mathrm{~d}, J=11.6 \mathrm{~Hz}, 1 \mathrm{H}), 4.18(\mathrm{~m}, 1 \mathrm{H}), 4.03(\mathrm{~m}$, $1 \mathrm{H}), 3.96-3.89(\mathrm{~m}, 2 \mathrm{H}), 3.87-3.80(\mathrm{~m}, 3 \mathrm{H}), 3.67(\mathrm{br} \mathrm{s}, 1 \mathrm{H}), 3.57-3.50(\mathrm{~m}, 2 \mathrm{H}), 3.49-3.44(\mathrm{~m}$, 2H), $2.18(\mathrm{br} \mathrm{s}, 1 \mathrm{H}), 2.11(\mathrm{t}, J=7.3 \mathrm{~Hz}, 2 \mathrm{H}), 1.58-1.56(\mathrm{~m}, 3 \mathrm{H}), 1.45(\mathrm{~m}, 1 \mathrm{H}), 1.24(\mathrm{br} \mathrm{s}, 68 \mathrm{H})$, $0.87(\mathrm{~m}, 6 \mathrm{H}) ;{ }^{13} \mathrm{C}$ NMR $\left(125 \mathrm{MHz} \mathrm{CDCl}_{3}\right) \delta 173.3,137.8,137.8,137.6,128.7,128.3,128.2$, $128.2,128.2,127.9,99.1,78.3,76.4,75.9,74.7,74.0,73.5,72.9,70.1,69.0,67.9,61.0,49.7$, 
37.0, 33.5, 32.1, 29.9, 29.8, 29.6, 29.6, 29.5, 26.1, 25.9, 22.9, 14.3; HRMS (ESI) calculated for $\mathrm{C}_{71} \mathrm{H}_{116} \mathrm{~N}_{4} \mathrm{NaO}_{8}(\mathrm{M}+\mathrm{Na})^{+} \mathrm{m} / \mathrm{z}: 1175.8685$. Found: 1175.8670 .

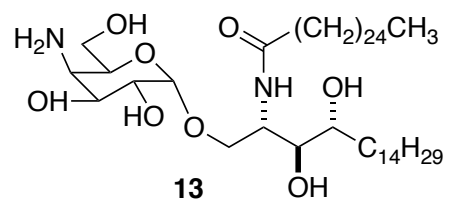

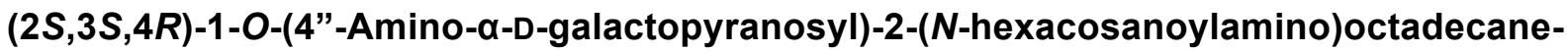

1,3,4-triol (13). $\mathrm{Pd}(\mathrm{OH})_{2}(20 \%$ on carbon, $120 \mathrm{mg})$ was added to a stirred solution of (2S,3S,4R)-1-O-(2",3",6"-tri-O-benzyl-4"-azido-a-D-galactopyranosyl)-2-N-hexacosanoylamino)octadecane-1,3,4-triol (B) $(50 \mathrm{mg}, 0.04 \mathrm{mmol})$ in $\mathrm{EtOH}(4 \mathrm{~mL})$ and $\mathrm{CHCl}_{3}(2 \mathrm{~mL})$. The mixture was stirred vigorously under $\mathrm{H}_{2}(1 \mathrm{~atm})$ for $12 \mathrm{~h}$. The reaction mixture was filtered through Celite, and the filter cake was washed with $50: 50 \mathrm{CHCl}_{3} / \mathrm{MeOH}$. The filtrate was concentrated, and the residue was triturated with EtOAc $(3 \times 5 \mathrm{~mL})$ to afford 13 as a white solid $(33 \mathrm{mg}, 88 \%)$ : $\mathrm{mp} \mathrm{204-206}{ }^{\circ} \mathrm{C} ;[\alpha]^{25}{ }_{\mathrm{D}}+42.0(\mathrm{c} 0.3,50: 50 \mathrm{DCM} / \mathrm{MeOH}) ;$ IR (neat) 3311 (br), 2916, 2849, 1642, $1027 \mathrm{~cm}^{-1} ;{ }^{1} \mathrm{H}$ NMR $\left(500 \mathrm{MHz}\right.$, pyr- $\left.d_{5}\right) \delta 5.53(\mathrm{~m}, 1 \mathrm{H}), 5.24(\mathrm{~m}, 1 \mathrm{H}), 4.66(\mathrm{~m}, 2 \mathrm{H}), 4.60(\mathrm{dd}, J=$ 10.6, $5.3 \mathrm{~Hz}, 1 \mathrm{H}), 4.46(\mathrm{dd}, J=11.9,11.9 \mathrm{~Hz}, 1 \mathrm{H}), 4,40-4.30(\mathrm{~m}, 5 \mathrm{H}), 4.17(\mathrm{dd}, J=11.9,4.9$ $\mathrm{Hz}, 1 \mathrm{H}), 2.51-2.48(\mathrm{~m}, 2 \mathrm{H}), 2.24(\mathrm{~m}, 1 \mathrm{H}), 1.90-1.79(\mathrm{~m}, 4 \mathrm{H}), 1.67-1.65(\mathrm{~m}, 1 \mathrm{H}), 1.30(\mathrm{~m}, 68 \mathrm{H})$, $0.85(\mathrm{~m}, 6 \mathrm{H}) ;{ }^{13} \mathrm{C}$ NMR $\left(125 \mathrm{MHz}, \mathrm{pyr}-d_{5}\right) \delta 174.0,101.3,76.9,73.1,70.8,69.3,68.8,68.4$, $60.6,54.4,51.8,37.3,34.8,32.6,30.9,30.7,30.5,30.5,30.4,30.4,30.4,30.3,30.3,30.1,27.0$, 26.9, 23.4, 14.8; HRMS (ESI) calculated for $\mathrm{C}_{50} \mathrm{H}_{101} \mathrm{~N}_{2} \mathrm{O}_{8}(\mathrm{M}+\mathrm{H})^{+} \mathrm{m} / \mathrm{z}$ : 857.7552. Found: 857.7523. 


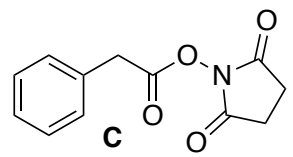

Benzeneacetic acid succinimide ester (C). EDC HCl $(1.8 \mathrm{~g}, 9.5 \mathrm{mmol})$ and succinimide $(1.3 \mathrm{~g}$, $11 \mathrm{mmol})$ were added to a solution of phenyl acetic acid $(1.0 \mathrm{~g}, 7.3 \mathrm{mmol})$ in DCM $(30 \mathrm{~mL})$, and the solution was stirred at $40^{\circ} \mathrm{C}$ overnight. The reaction mixture was concentrated and purified by flash chromatography on silica gel (petroleum ether/EtOAc 80:20) to yield $\mathbf{C}$ as a white solid $(0.90 \mathrm{~g}, 58 \%):{ }^{1} \mathrm{H}$ NMR $\left(300 \mathrm{MHz}, \mathrm{CDCl}_{3}\right) \delta$ 7.32-7.23 (m, 5H), $3.91(\mathrm{~s}, 2 \mathrm{H}), 2.79(\mathrm{~s}, 4 \mathrm{H})$.<smiles>O=C(CCc1ccccc1)ON1C(=O)CCC1=O</smiles>

Benzenepropanoic acid succinimide ester (D). $\mathrm{EDC} \cdot \mathrm{HCl}(1.7 \mathrm{~g}, 8.7 \mathrm{mmol})$ and succinimide $(1.1 \mathrm{~g}, 10 \mathrm{mmol})$ were added to a solution of hydrocinnamic acid $(1.0 \mathrm{~g}, 6.7 \mathrm{mmol})$ in DCM (30 $\mathrm{mL}$ ), and the solution was stirred at $40^{\circ} \mathrm{C}$ overnight. The reaction mixture was concentrated and purified by flash column chromatography on silica gel (petroleum ether/EtOAc 80:20) to yield D as a white solid $(0.80 \mathrm{~g}, 51 \%):^{6-7}{ }^{1} \mathrm{H}$ NMR $\left(400 \mathrm{MHz}, \mathrm{CDCl}_{3}\right) \delta 7.34-7.24(\mathrm{~m}, 5 \mathrm{H}), 3.09(\mathrm{t}, \mathrm{J}=$ $8.0 \mathrm{~Hz}, 2 \mathrm{H}), 2.95(\mathrm{t}, J=8.0 \mathrm{~Hz}, 2 \mathrm{H}), 2.86(\mathrm{~s}, 4 \mathrm{H})$.

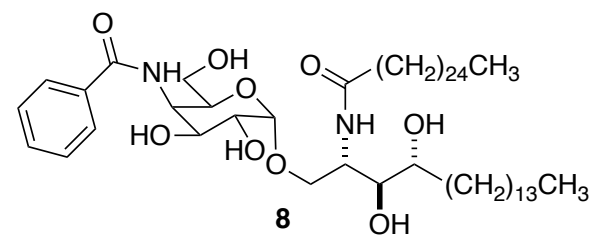

(2S,3S,4R)-1-O-(4"-N-Benzoylamino-a-D-galactopyranosyl)-2-(N-hexacosanoylaminooctadecane-1,3,4-triol (8). Benzoyl chloride (2.7 $\mu \mathrm{L}, 0.014 \mathrm{mmol})$ and $\mathrm{NEt}_{3}(1.5 \mu \mathrm{L}, 0.014 \mathrm{mmol})$ were added to a stirred solution of $(2 S, 3 S, 4 R)-1-O-(4$ "-amino- $\alpha-D-g a l a c t o p y r a n o s y l)-2-(N-$ hexacosanoylamino)octadecane-1,3,4-triol (13) (10 mg, 0.012 mmol) in DCM/MeOH (0.7 mL:0.3 
$\mathrm{mL}$ ). The reaction mixture was stirred at RT for $24 \mathrm{~h}$. The mixture was concentrated and purified by flash chromatography on silica gel $\left(\mathrm{CH}_{2} \mathrm{Cl}_{2} / \mathrm{MeOH} 90: 10\right)$ to afford 8 as a white solid $(2.0 \mathrm{mg}$, 18\%): mp $124-126^{\circ} \mathrm{C} ;[\alpha]^{25}{ }_{\mathrm{D}}+8.8\left(\right.$ c 0.1, 80:20 DCM/MeOH); ${ }^{1} \mathrm{H}$ NMR $(500 \mathrm{MHz}$, $\left.\mathrm{CDCl}_{3} / \mathrm{CD}_{3} \mathrm{OD}\right) \delta 7.55(\mathrm{~d}, J=7.2 \mathrm{~Hz}, 2 \mathrm{H}), 7.27-7.17(\mathrm{~m}, 3 \mathrm{H}), 4.69(\mathrm{~d}, J=4.0 \mathrm{~Hz}, 1 \mathrm{H}), 4.33(\mathrm{~d}, J$ $=2.8 \mathrm{~Hz}, 1 \mathrm{H}), 3.94(\mathrm{~m}, 1 \mathrm{H}), 3.82-3.75(\mathrm{~m}, 2 \mathrm{H}), 3.63(\mathrm{dd}, J=10.7,4.6 \mathrm{~Hz}, 1 \mathrm{H}), 3.50(\mathrm{dd}, J=$ 10.2, $4.0 \mathrm{~Hz}, 1 \mathrm{H}), 3.45(\mathrm{dd}, J=10.5,4.0 \mathrm{~Hz}, 1 \mathrm{H}), 3.39(\mathrm{~m}, 1 \mathrm{H}), 3.35-3.30(\mathrm{~m}, 3 \mathrm{H}), 1.95(\mathrm{t}, J=$ $7.5 \mathrm{~Hz}, 2 \mathrm{H}), 1.41-1.29(\mathrm{~m}, 4 \mathrm{H}), 0.99$ (br s, 68H), $0.61(\mathrm{~m}, 6 \mathrm{H}) ;{ }^{13} \mathrm{C}$ NMR $(125 \mathrm{MHz}, \mathrm{CDCl}-$ $\left.{ }_{3} / \mathrm{CD}_{3} \mathrm{OD}\right) \delta 174.4,171.1,133.7,131.7,128.3,127.2,99.3,74.3,71.7,69.6,69.1,69.1,67.2$ $61.2,52.0,50.1,36.2,32.2,31.7,29.5,29.4,29.2,29.1,25.6,22.4,13.6$; HRMS (ESI) calculated for $\mathrm{C}_{57} \mathrm{H}_{104} \mathrm{~N}_{2} \mathrm{NaO}_{9}(\mathrm{M}+\mathrm{Na})^{+} \mathrm{m} / \mathrm{z}$ : 983.7634. Found: 983.7637 .

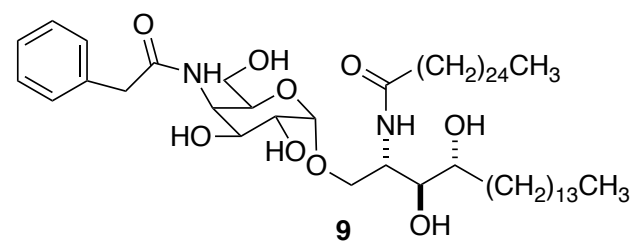

(2S,3S,4R)-1-O-(4"'-N-Phenylacetylamino- $\alpha-D-g a l a c t o p y r a n o s y l)-2-(N-h e x a c o s a n-$ oylamino)octadecane-1,3,4-triol (9). Phenylacetic acid succinimide ester (C) (1.4 mg, 0.0065 $\mathrm{mmol})$ was added to a stirred solution of $(2 S, 3 S, 4 R)-1-O-(4$ "-amino- $\alpha-\mathrm{D}-$ galactopyranosyl)-2-(Nhexacosanoylaminooctadecane-3,4-diol (13) $(5.0 \mathrm{mg}, 0.0060 \mathrm{mmol})$ in $\mathrm{NEt}_{3}(1.6 \mathrm{uL}, 0.012$ $\mathrm{mmol}$ ) and DMF (1 mL). The reaction mixture was stirred at RT for $24 \mathrm{~h}$. The mixture was concentrated and purified by flash chromatography on silica gel (DCM/MeOH 90:10) to afford 9 as an off white solid (3.0 mg, 51\%): mp 120-122 ${ }^{\circ} \mathrm{C} ;[\alpha]^{25}-4.3(c 0.1,80: 20 \mathrm{DCM} / \mathrm{MeOH}) ;{ }^{1} \mathrm{H}$ NMR (500 MHz, pyr- $\left.d_{5}\right) \delta 8.85(\mathrm{~d}, J=9.1 \mathrm{~Hz}, 1 \mathrm{H}), 8.48(\mathrm{~d}, J=8.5 \mathrm{~Hz}, 1 \mathrm{H}), 7.48(\mathrm{~d}, J=7.3 \mathrm{~Hz}$, 2H), 7.26-7.18 (m, 3H), $5.42(\mathrm{~m}, 1 \mathrm{H}), 5.22(\mathrm{~m}, 1 \mathrm{H}), 5.12(\mathrm{~m}, 1 \mathrm{H}), 4.64-4.57(\mathrm{~m}, 3 \mathrm{H}), 4.41(\mathrm{~m}$, 1H), 4.36-4.30 (m, 3H), $4.11(\mathrm{~m}, 1 \mathrm{H}), 4.05(\mathrm{~m}, 1 \mathrm{H}), 3.83(\mathrm{~m}, 2 \mathrm{H}), 3.61(\mathrm{~s}, 2 \mathrm{H}), 2.64(\mathrm{~s}, 1 \mathrm{H})$, 2.47-2.41 (m, 2H), $2.27(\mathrm{~m}, 1 \mathrm{H}), 1.90-1.80(\mathrm{~m}, 4 \mathrm{H}), 1.66(\mathrm{~m}, 1 \mathrm{H}), 1.29(\mathrm{br} \mathrm{s}, 68 \mathrm{H}), 0.88(\mathrm{~m}$, 
$6 \mathrm{H}) ;{ }^{13} \mathrm{C}$ NMR $\left(125 \mathrm{MHz}\right.$, pyr- $\left.d_{5}\right) \delta$ 173.8, $173.6,130.1,129.1,127.3,101.5,77.1,72.9,72.2$, $70.8,70.0,69.2,62.5,53.0,51.6,50.1,43.7,37.2,34.8,32.6,30.8,30.6,30.5,30.5,30.4,30.3$, $30.3,30.2,30.1,26.9,26.8,26.5,23.4,14.7$; HRMS (ESI) calculated for $\mathrm{C}_{58} \mathrm{H}_{106} \mathrm{~N}_{2} \mathrm{NaO}_{9}(\mathrm{M}+$ $\mathrm{Na})^{+} \mathrm{m} / \mathrm{z}:$ 997.7791. Found: 997.7793.

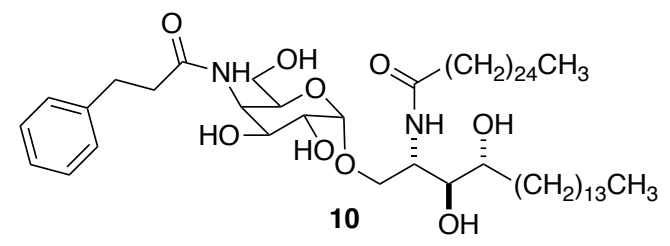

$(2 S, 3 S, 4 R)-1-O-(4$ "-N-Hydrocinnamoylamino- $\alpha-D-g a l a c t o p y r a n o s y l)-2-(N-h e x a-$

cosanoylamino)octadecane-1,3,4-triol (10). Phenyl propanoic acid succinimide ester (D) (6.0 $\mathrm{mg}, 0.025 \mathrm{mmol})$ was added to a stirred solution of $(2 S, 3 S, 4 R)-1-(4$ "-amino- $\alpha-\mathrm{D}$ galactopyranosyl)-2-hexacosanoyl aminooctadecane-3,4-diol (13) (10 mg, $0.012 \mathrm{mmol}$ ) in $\mathrm{NEt}_{3}$ (3.5 uL, $0.025 \mathrm{mmol})$ and DMF $(0.5 \mathrm{~mL})$. The reaction mixture was stirred at RT for $24 \mathrm{~h}$. The mixture was concentrated and purified by flash chromatography on silica gel (DCM/MeOH 90:10) to afford 10 as a white solid (3.0 mg, $25 \%$ ): mp $126-128^{\circ} \mathrm{C}$; $[\alpha]^{25}{ }_{D}+1.4(\mathrm{c} 0.1,80: 20$ DCM/MeOH); ${ }^{1} \mathrm{H}$ NMR (500 MHz, $\left.\mathrm{CDCl}_{3} / \mathrm{CD}_{3} \mathrm{OD}\right) \delta$ 7.04-6.91 (m, 5H), $4.60(\mathrm{~d}, J=4.1 \mathrm{~Hz}, 1 \mathrm{H})$, $4.06(\mathrm{dd}, J=4.5,1.2 \mathrm{~Hz}, 1 \mathrm{H}), 3.92(\mathrm{ddd}, J=4.4,4.4,4.4 \mathrm{~Hz}, 1 \mathrm{H}), 3.78(\mathrm{~s}, 1 \mathrm{H}), 3.67-3.63(\mathrm{~m}$, 2H), $3.59(\mathrm{dd}, J=10.8,4.8 \mathrm{~Hz}, 1 \mathrm{H}$ ), $3.39(\mathrm{dd}, J=10.8,4.2 \mathrm{~Hz}, 1 \mathrm{H}), 3.35(\mathrm{dd}, J=10.2,4.0 \mathrm{~Hz}$, 1H), 3.29-3.27 (m, 2H), $3.07(\mathrm{dd}, J=11.7,6.8 \mathrm{~Hz}, 1 \mathrm{H}), 2.99(\mathrm{dd}, J=11.8,6.2 \mathrm{~Hz}, 1 \mathrm{H}), 2.69(\mathrm{t}$, $J=7.1 \mathrm{~Hz}, 2 \mathrm{H}), 2.35(\mathrm{t}, J=8.1 \mathrm{~Hz}, 2 \mathrm{H}), 1.94(\mathrm{t}, J=7.6 \mathrm{~Hz}, 2 \mathrm{H}), 1.42-1.28(\mathrm{~m}, 4 \mathrm{H}), 1.04(\mathrm{br} \mathrm{s}$, $68 \mathrm{H}), 0.62(\mathrm{~m}, 6 \mathrm{H}) ;{ }^{13} \mathrm{C} N M R\left(125 \mathrm{MHz}, \mathrm{CDCl}_{3} / \mathrm{CD}_{3} \mathrm{OD}\right) \delta 175.7,174.3,140.5,128.3,128.1$, $126.0,99.2,74.4,71.7,69.6,68.9,68.7,67.2,60.8,50.9,50.1,37.4,36.2,32.3,31.7,31.5$, 29.6, 29.5, 29.5, 29.4, 29.3, 29.2, 29.1, 25.6, 25.6, 22.4, 13.6; HRMS (ESI) calculated for $\mathrm{C}_{59} \mathrm{H}_{108} \mathrm{~N}_{2} \mathrm{NaO}_{9}(\mathrm{M}+\mathrm{Na})^{+} \mathrm{m} / \mathrm{z}:$ 1011.7947. Found: 1011.7938 . 


\section{References:}

1. Chennamadhavuni, D.; Saavedra-Avila, N. A.; Carreño, L. J.; Guberman-Pfeffer, M. J.; Arora, P.; Yongqing, T.; Pryce, R.; Koay, H. F.; Godfrey, D. I.; Keshipeddy, S.; Richardson, S. K.; Sundararaj,' S.; Lo, J. H.; Wen, X.; Gascón, J. A.; Yuan, W.; Jamie Rossjohn, J.; Le Nours, J.; Steven A. Porcelli, S. A.; Howell, A. R., Dual Modifications of a-Galactosylceramide Synergize to Promote Activation of Human Invariant Natural Killer T Cells and Stimulate Antitumor Immunity. Cell Chem. Biol. 2018, 25, 571-584.

2. Xia, C.; Zhang, W.; Zhang, Y.; Chen, W.; Nadas, J.; Severin, R.; Woodward, R.; Wang, B.; Wang, X.; Kronenberg, M.; Wang, P. G., The Roles of 3' and 4' Hydroxy Groups in alphaGalactosylceramide Stimulation of Invariant Natural Killer T Cells. ChemBioChem 2009, 4, 1810-1815.

3. Xia, C.; Yao, Q.; Schumann, J.; Rossy, E.; Chen, W.; Zhu, L.; Zhang, W.; Libero, G. D.; Wang, P. G., Synthesis and Biological Evaluation of a-Galactosylceramide (KRN7000) and Isoglobotrihexosylceramide (iGb3). Bioorg. Med. Chem. Lett. 2006, 16, 2195-2199.

4. $\quad \mathrm{Bi}$, J.; Wang, J.; Zhou, K.; Wang, Y.; Fang, M.; Du, Y., Synthesis and Biological Activities of 5-Thio-a-GalCers. ACS Med. Chem. Lett. 2015, 6 (4), 476-480.

5. Stembera, K.; Buchynsky, A.; Vogel, S.; Knoll, D.; Osman, A. A.; Ayala, J. A.; Welzel, P., Moenomycin-mediated Affinity Purification of Penicillin-binding Protein 1b. ChemBioChem 2002, 3 (4), 332-340.

6. $\quad$ Chudinov, A. V.; Kiseleva, Y. Y.; Kuznetsov, V. E.; Shershov, V. E.; Spitsyn, M. A.; Guseinov, T. O.; Lapa, S. A.; Timofeev, E. N.; Archakov, A. I.; Lisitsa, A. V.; Radko, S. P.; Zasedatelev, A. S., Structural and Functional Analysis of Biopolymers and their Complexes: Enzymatic Synthesis of High-modified DNA. Mol. Biol. (Moscow, Russ. Fed., Engl. Ed.) 2017, 51 (3), 474-482.

7. Rodriguez, M.; Dubreuil, P.; Bali, J. P.; Mainez, J., Synthesis and Biological Activity of Partially Modified Retro-inverso Pseudopeptide Derivatives of the C-Terminal Tetrapeptide of Gastrin. J. Med. Chem. 1987, 30 (5), 758-63. 


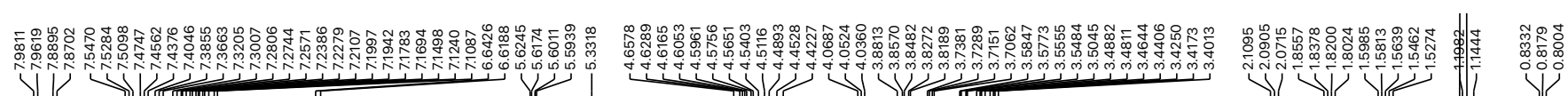
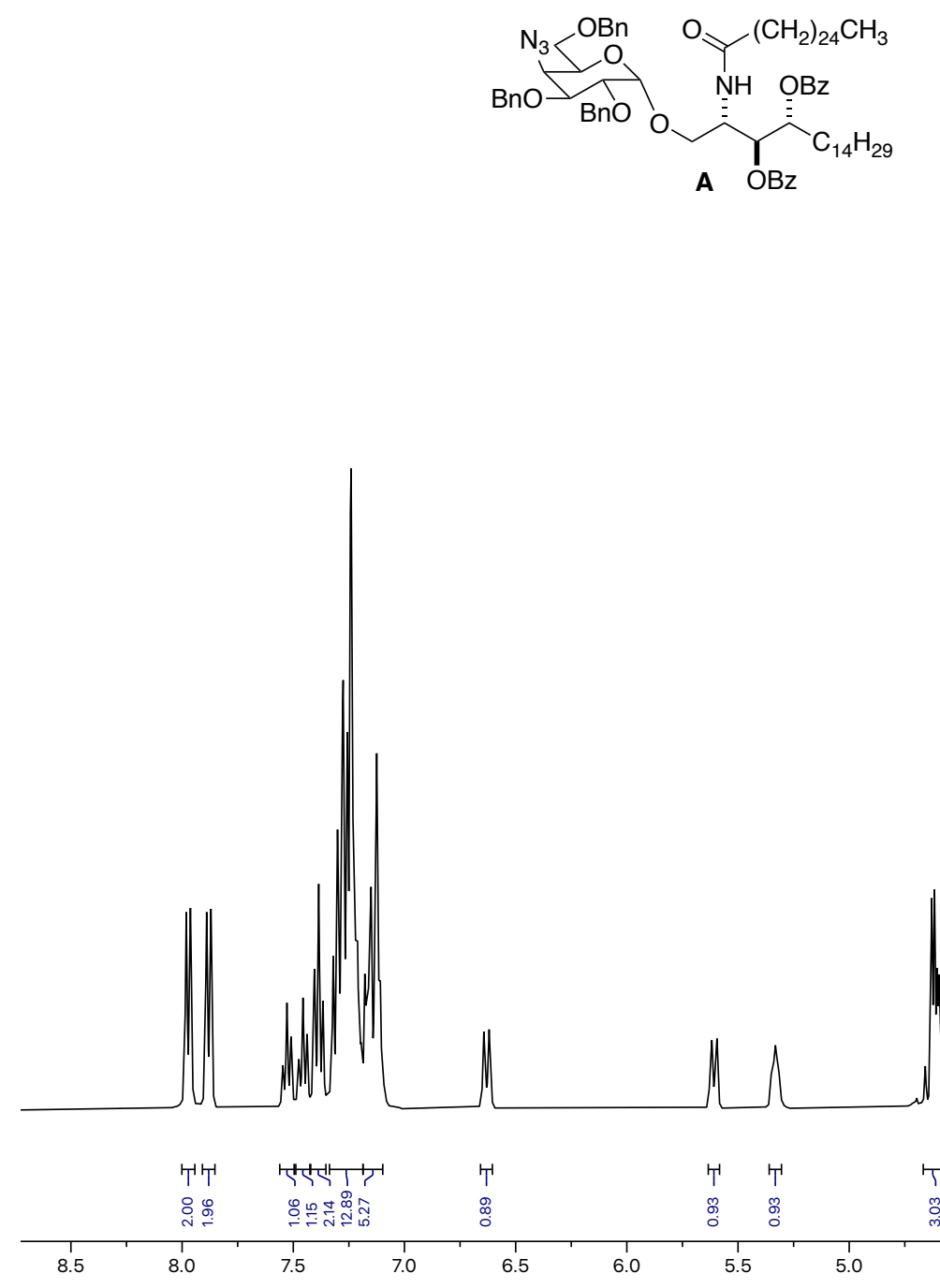

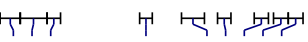

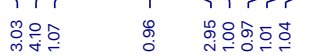

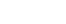



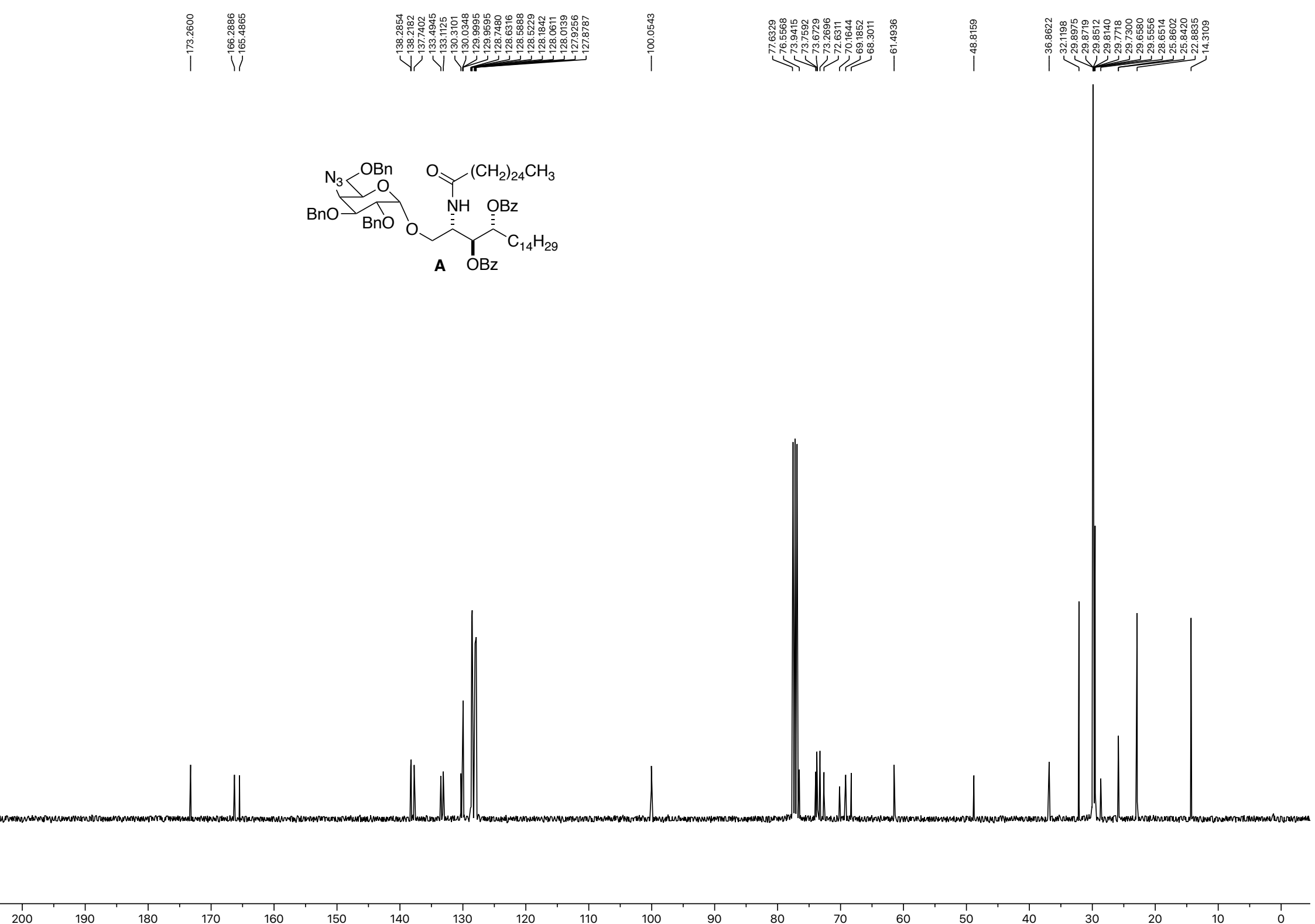


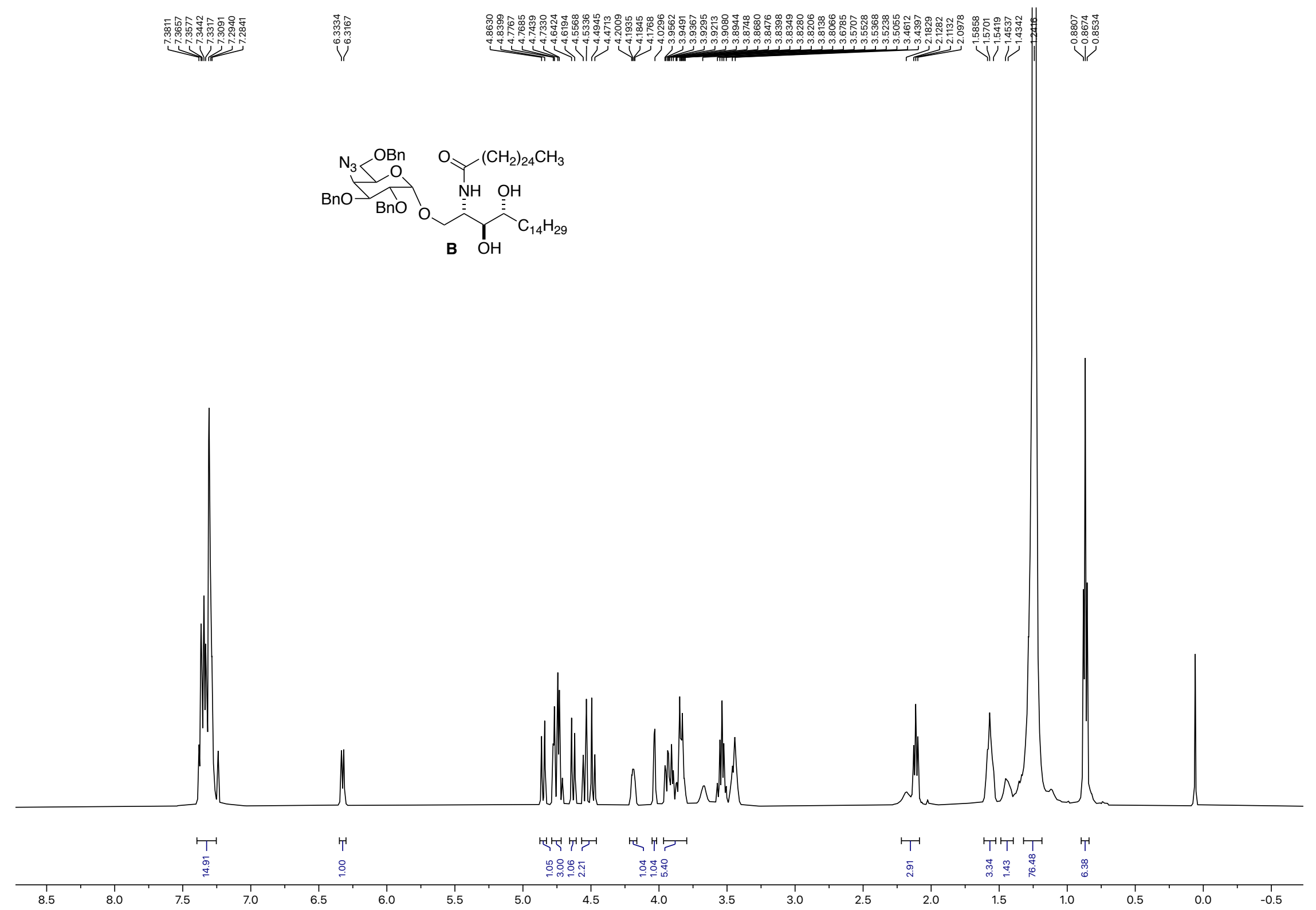




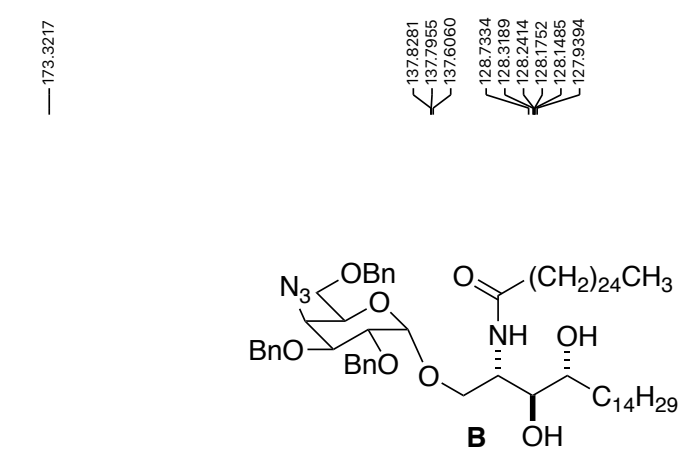

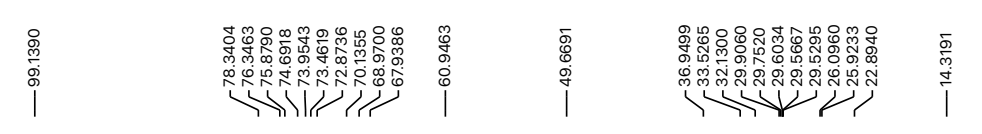

$$
\underbrace{C_{O H}}_{B}
$$

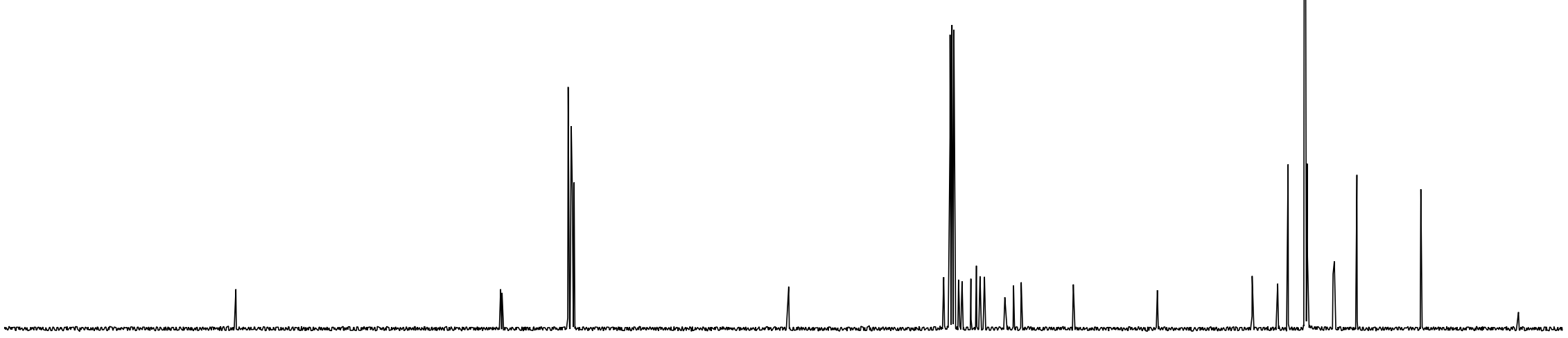




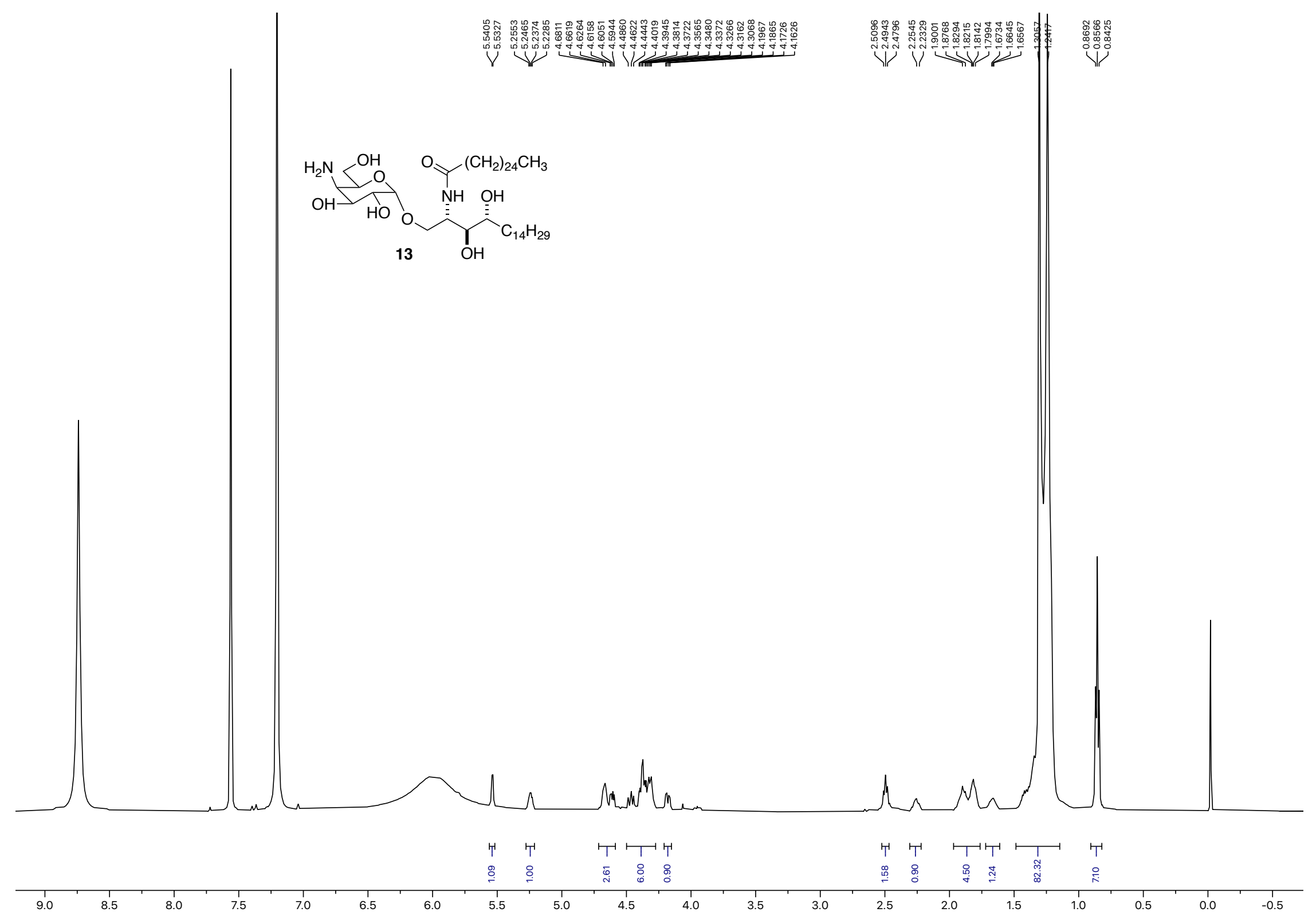




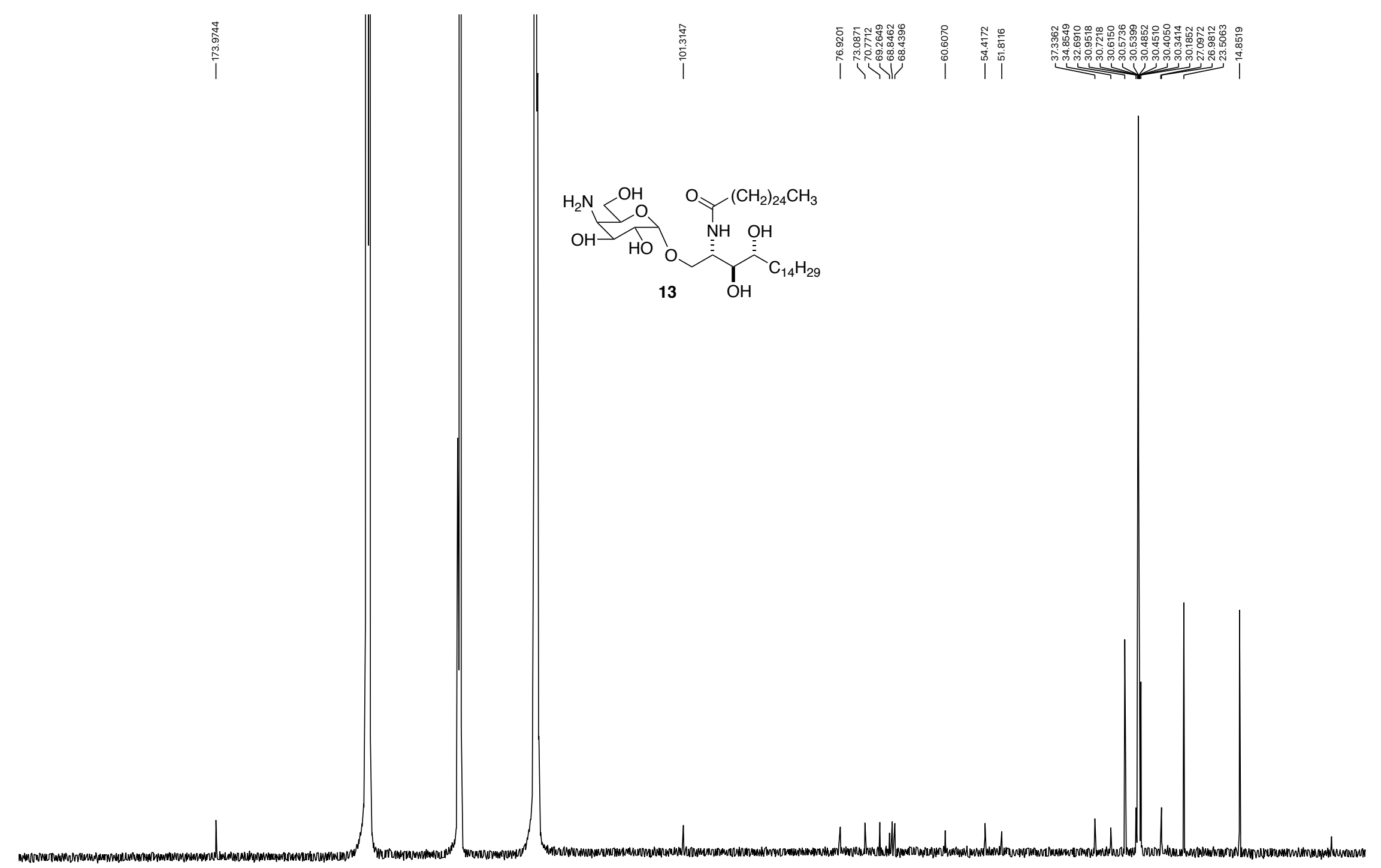




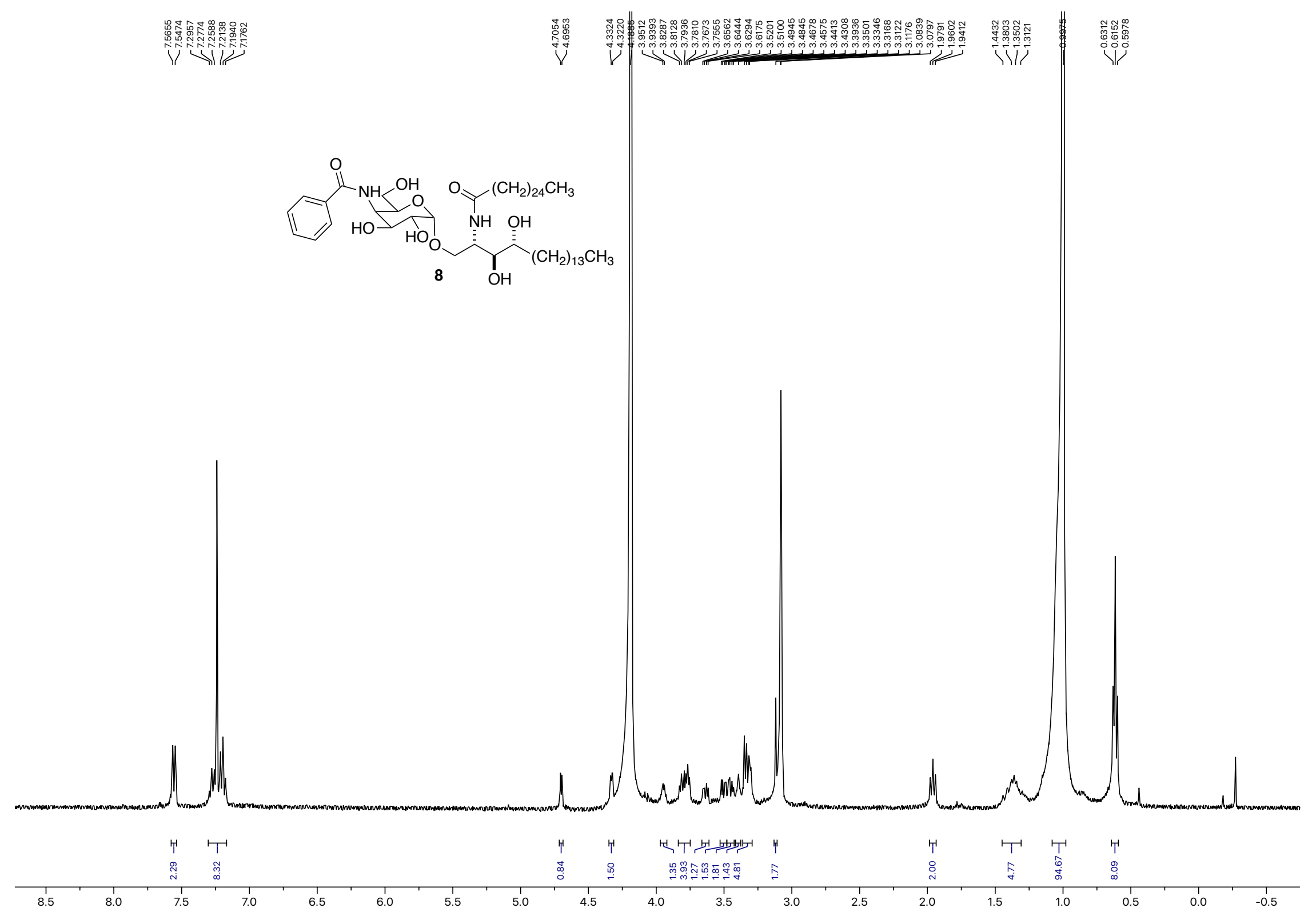



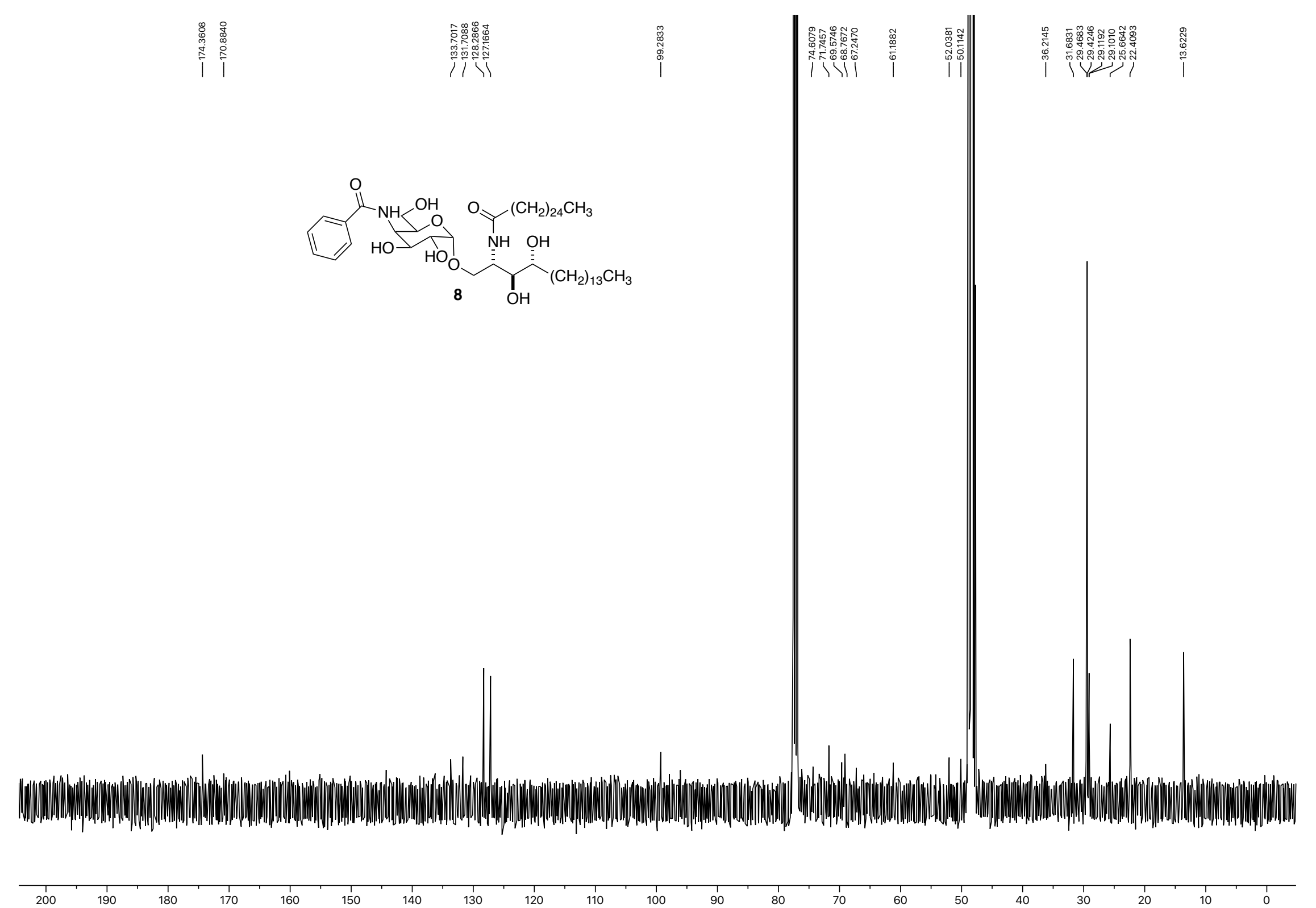


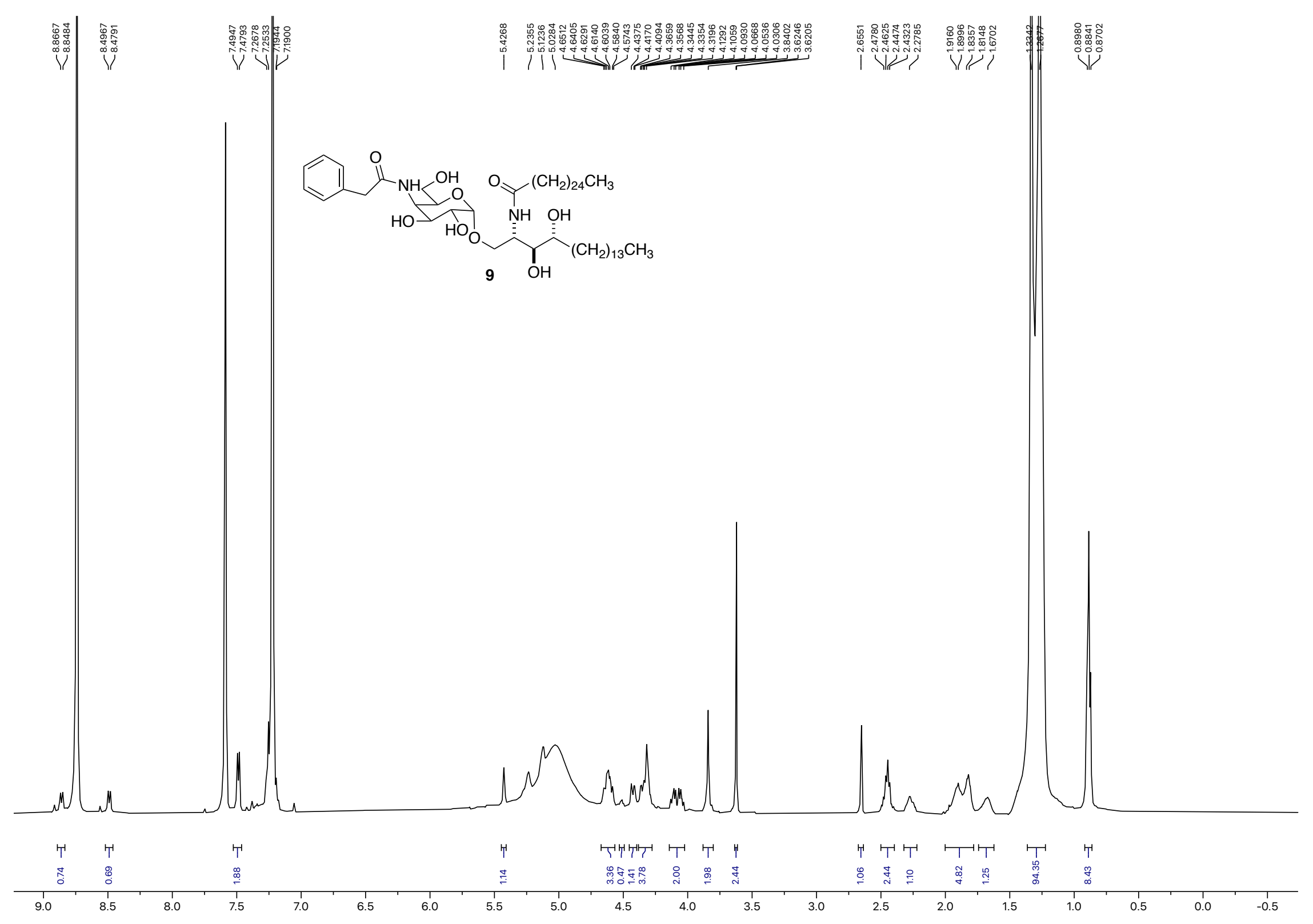



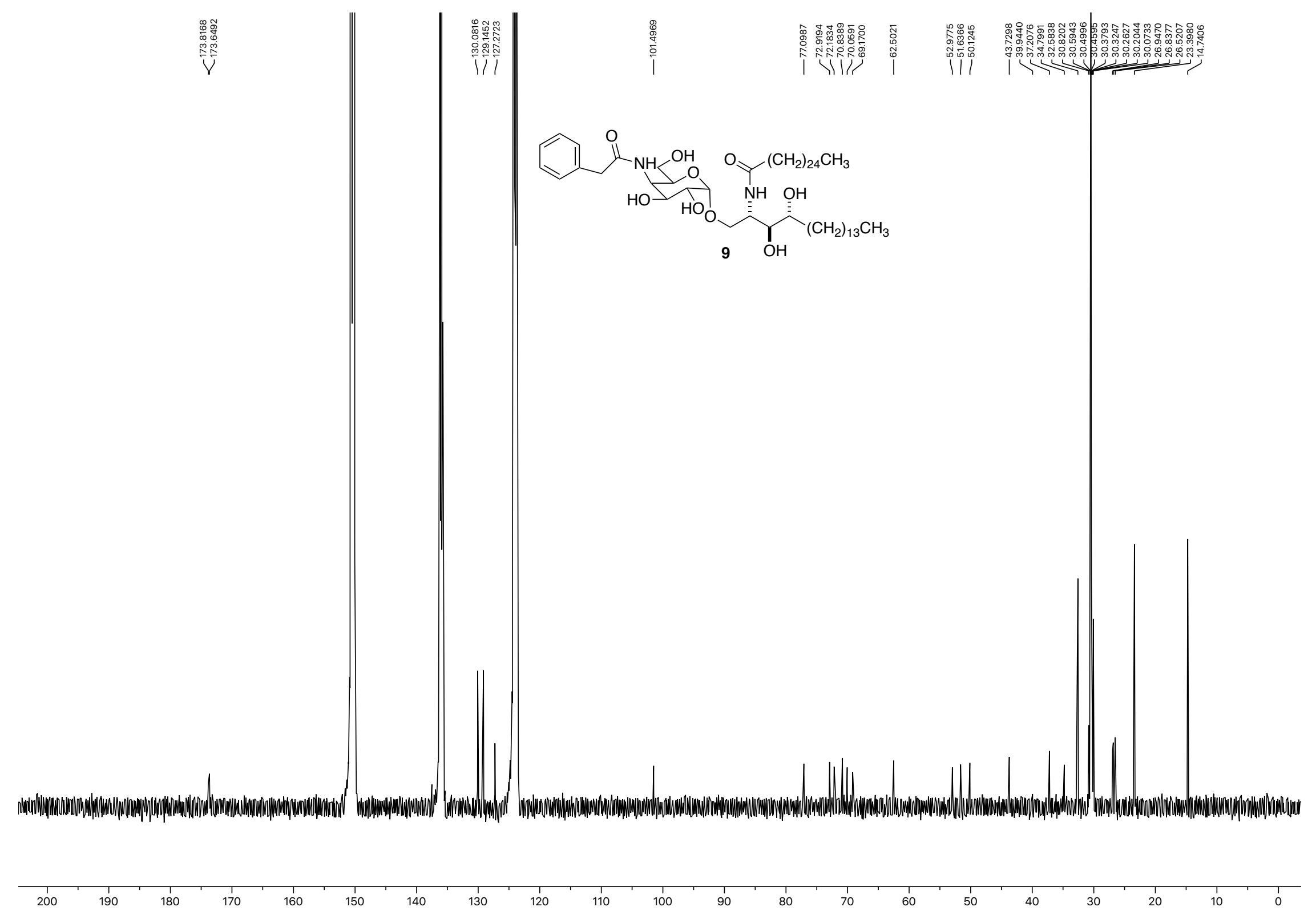


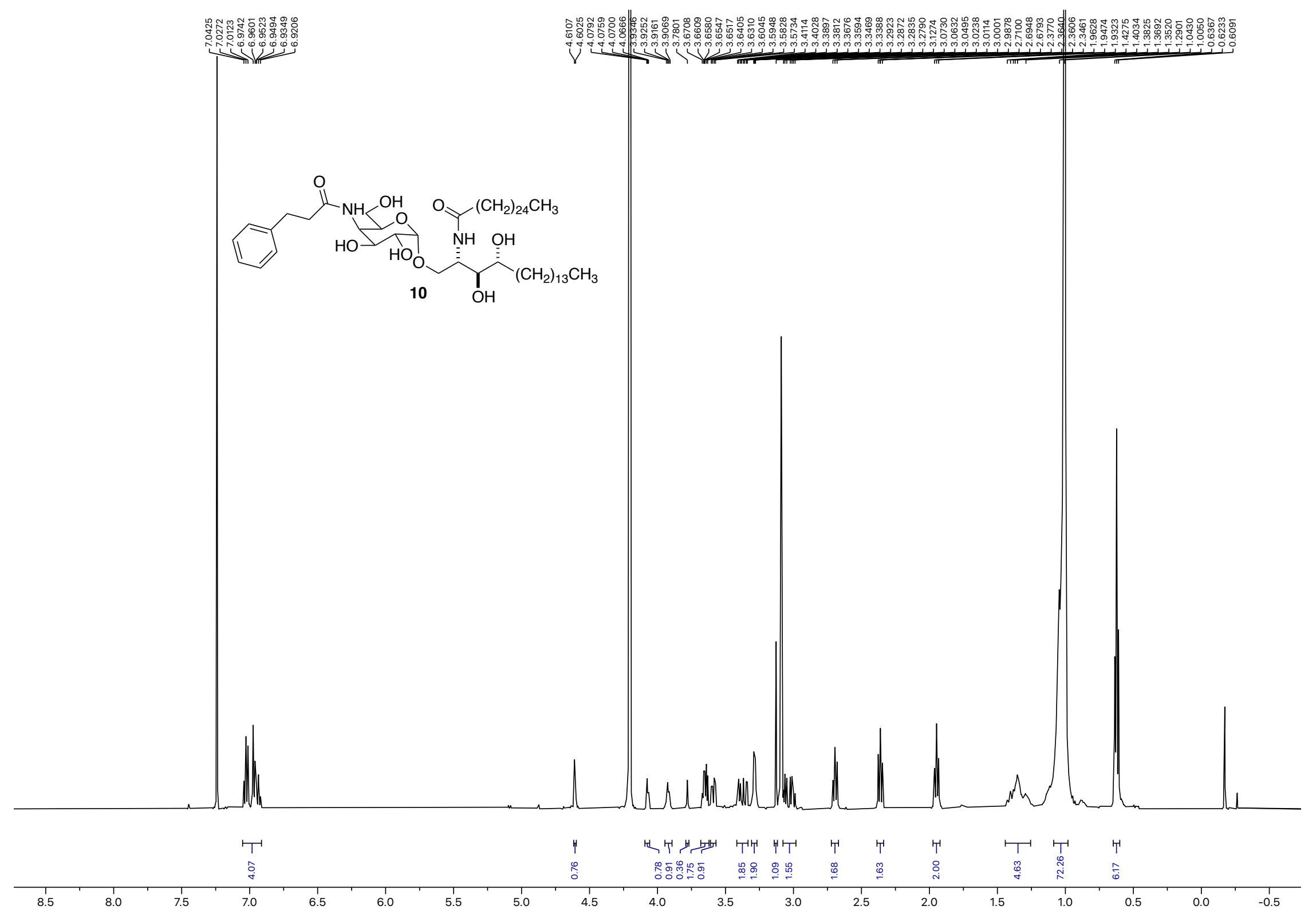




$$
+\pi
$$

